\title{
SIMULATION OF VIRTUAL TIME NORMS FOR TECHNOLOGICAL PROCESSES
}

\author{
Romualdas Tamošaitis ${ }^{1}$, Leonarda Gargasaite் ${ }^{2}$ \\ Dept of Construction Technology and Management. Vilnius Gediminas Technical University (VGTU), \\ Sauletekioal.11,LT-2040Vilnius, Lithuania, e-mail: ${ }^{1}$ roma@adm.vtu.lt, ${ }^{2}$ leonardai@one.lt
}

Received 18 April, 2003

\begin{abstract}
The methodology presented in the article is based on the simulation of technological process duration, restricting on the available information about total duration of complex technological process in the conditions when there are no possibilities to determine the time norm by traditional methods. This methodology allows determining the time norm of repetitive technological processes with a defined probability without additional measurement of time for every technological process. When more information about the duration of complex technological process duration is gathered, the methodology lets to make the additional correction of separate process time norm, also increasing the reliability of the revised time norm. The methodology lets to reduce the number of technological process duration measurements, promptly evaluate the objective changes of the time norm, occurred because of the new technologies, new equipment and skills of workers.
\end{abstract}

Keywords: time norm, technological process, simulation, construction

\section{Introduction}

Time norms are very important for the manufacturing companies, especially for civil engineering companies [1-5]. The process of creating the norms requires large expenditures of time [6]. Therefore sometimes companies use the norms that do not evaluate new materials and new technologies and uncertainty enough [7]. Applying such norms for calculation of work duration, big errors appear that are inconvenient for the proper organisation of works. Accuracy of planning depends on the nature and technical validity of norms and proper application in practice.

\section{Traditional methods of creating time norms}

Depending on the purpose and accuracy of observation, the methods for creating time norms are used $[6,7]$ :

- Technical record. The fulfilment degree of norms in force is tested by this method. The actual labour expenditures are compared with the standards and conclusions are made.
- Moment observation. This method is used when the level of shift working time fund usage is analysed. The fulfilment degree of existing norms may be determined. The work of one machine or worker is not observed and labour expenditure, but not separate moments are recorded.

- Use of stopwatch. The observed work process is divided into work elements by fixation points. There are several ways to use the stopwatch.

Selective way. This method is used for cyclic processes with repetitive operations. The observer knowing start and finish fixation points of the work element turns on the stopwatch, stops it and writes the time. After a certain number of observations the chronometric row, containing all recorded durations of a work element, is obtained. The duration average of each element is calculated. If values of a chronometric row are very close to separate work elements, the average is obtained by adding all the values and dividing by the number of observations. However, if values differ widely, time is measured many times and the reasons of variation are analysed. The number of time meas- 
urement is related to the permanence coefficient of a chronometric row, which is calculated by formula:

$$
k_{p}=\frac{t_{\max }}{t_{\min }},
$$

where $t_{\max }$ is the maximum value of a chronometric row; $t_{\min }$ - the minimum value of a chronometric row.

Permanence coefficient describes the quality of a chronometric row: the smaller the coefficient, the steadier the row.

Continuous way. This method is used when the observed elements of a work process proceed in sequence and the finish time of one element coincides with the start time of the other element. In this way the duration of separate elements is determined, keeping their interrelationship. The continuous observation is carried out in the following way: starting the work two pointers of a stopwatch are released; when the first work element is finished one pointer is stopped and the time is recorded; when the second element is finished the second pointer is stopped and the first needle released and so on. The obtained data are analysed in the same way as using stopwatch and performing the observation in a selective way.

- Photo records. Using this method all labour expenditures are analysed and the necessary data are obtained. Depending on the number of workers required to perform a certain process, photo record may be individual or team.

- Using a video recorder. Continuous work process may be obtained in this way. The video recorder may be equipped with a time and date generator, so that the exact time of recording each image will appear on the monitor. This method allows evaluating exactly all labour expenditures of the latter analysed work elements.

- Workday picture. Making the workday picture, continuous observation of all labour expenditures is performed, the necessary data for creating the norms are obtained. Photo records and the use of stopwatch supplement workday picture.

All methods of observation allow complex evaluation of work duration, however because of the lack of methodology for handling the gathered data, usually separate processes are standardised and this requires much of additional time expenditures.

\section{Traditional methods for handling the gathered data}

The gathered data is analysed in such a way:

- The values of labour time expenditures are grouped according to the structural processes;

- Data row for each observed element is written in an increasing order;

- Analysis of the row is performed and the values that do not belong to the investigated normal are eliminated;

- Values of the row are checked using mathematical methods and the unnecessary ones are eliminated;

- The average of the ordered row is calculated.

At first the values differing widely that are obtained because of accidental factors are excluded. If different values are left, they should be repeatedly checked. Checking is made according to the permanency coefficient, which is the ratio of maximum and minimum values in a row [6]. According to the value of the coefficient, such variants are possible:

- If the coefficient is not more than 1,3 , it is assumed that the row is uniform enough and nothing should be excluded.

If the coefficient is between 1,3 and 2,0, the row is checked by the method of limit values. For checking different values for the first time, these approximate formulas are used:

$$
\begin{aligned}
& \lim A_{\max }=A_{a v}+K\left(A_{\max }-A_{\min }\right), \\
& \lim A_{\min }=A_{a v}-K\left(A_{\max }-A_{\min }\right),
\end{aligned}
$$

where $\lim A_{\max }, \lim A_{\min }$ are maximum and minimum allowable values of a row;

$A_{a v}$ - average value of a row;

$K$ - coefficient, depending on the number of values in a row.

Next checking the row data, the following formulas are applied:

$$
\begin{gathered}
\lim A_{\max } \leq \frac{\sum_{i=1}^{n} A_{i}-A_{n}}{n-1}+K\left(A_{n-1}-A_{1}\right), \\
\lim A_{\min } \geq \frac{\sum_{i=1}^{n} A_{i}-A_{1}}{n-1}-K\left(A_{n}-A_{1}\right),
\end{gathered}
$$


where $\sum_{i=1}^{n} A_{i}$ is sum of all values in a row;

$n$ - number of the values;

$K$ - coefficient, depending on the number of values in a row;

$A_{n}$ - maximum value in a row;

$A_{1}-$ minimum value in a row.

All values in a row should not overstep the determined limit values.

- If the coefficient is more than 2,0, the row is checked by the method of relative average square error. The determined relative average square error should not be bigger than the allowable one.

The allowable relative square error of the row depends on the number of cyclic elements in the work; for example, if there are up to 5 cyclic elements in a row, the allowable error is $\pm 7 \%$; if more than 5 , then $\pm 10 \%$.

The actual relative average square error is calculated by formula:

$$
e f= \pm \frac{100}{A_{a v}} \sqrt{\frac{\sum \Delta^{2}}{n(n-1)}}
$$

where

$A_{a v}$ is an average of the values in a row;

$\Delta-$ variation of each value in a row from the average value;

$n$ - number of measurements in a chronometric row.

If the actual value of the relative average square error is bigger than the allowable one, the values that differ most are eliminated from the row: from 10 values one is eliminated, from 25 two values and when there are more than 25 values, $10 \%$ of all values are eliminated. Which value - the maximum or minimum - should be excluded is determined by the method of average square error. Two coefficients are calculated:

$$
\begin{gathered}
K_{1}=\frac{\sum_{i=1}^{n} A_{i}-A_{1}}{\sum_{i=1}^{n} A_{i}-A_{n}}, \\
K_{2}=\frac{\sum_{i=1}^{n} A_{i}^{2}-A_{1} \sum_{i=1}^{n} A_{i}}{A_{n} \sum_{i=1}^{n} A_{i}-\sum_{i=1}^{n} A_{i}^{2}} .
\end{gathered}
$$

When $K_{1} \leq K_{2}$, the minimum value $A_{1}$ of the row is eliminated; when $K_{1} \geq K_{2}$, the maximum one $A_{n}$. If after elimination of an intended number of values, the actual relative square error is bigger than the allowable, one can conclude that the rows are made not precisely enough and that the observations should be continued further on.

\section{Concept of the virtual time norm}

Virtual time norm is understood as probabilistically evaluated constantly revised time norm for complex typical works, determined according to the actual durations of the finished product creation stages [8, 9]. Such norms may be estimated for specialised works, consisting of limit number of separate different size technological processes, but performed by the same team working with certain technological equipment.

The method offered is applicable for time rating of typical technological processes performed by a specialized group of workers with the available equipment and ordinary technology. The methodology lets to evaluate the objective changes of the time norm, occurred because of the new technologies, new equipment and skills of workers, however it is not applied in that cases, when the duration of technological process is influenced by such casual factors as shortage of materials or bad weather conditions, that influence is hardly foreseen. It is recommended to apply the methodology for the processes, performed inside the room or for these, that are not influenced by weather conditions. If it is not possible to avoid the casual factors, special analysis for determination of influence of subjective factors to technological process duration should be performed and during estimation of the time norm the time losses occurred because of that reasons should be eliminated.

\section{Evaluation of virtual time norm}

If one would fix the duration of a complex technological process consisting of $\mathrm{n}$ technological processes for $m$ times, where $m^{3} n$, one could write a system of equations and mathematically find the unknown variables of the system.

In this work duration and amount of the works performed are related by linear. Repeating the work several times, the time norm is changing. Part of these changes is objective and based on the theoretical arguments, for example, influence of the repetition effect; another part of the changes is of stochastic na- 
ture, what should also be evaluated with a corresponding probability. According to the traditional methods of time rating [6], the values of work duration that differ from the average signally are eliminated. When methodology presented here is applied, this can't be done; therefore time norm of the work is determined with corresponding reliability. The way of determination reliability is presented thereinafter. The maximum allowable variation could be defined by standard deviation $-\mathrm{s}$. The system of equations for complex works is presented below.

$$
\left\{\begin{array}{l}
\sum_{j=1}^{n} K_{1 j} \cdot q_{1 j} \cdot k_{1 j}=T_{1} \cdot Q_{1}, \\
\ldots, \\
\sum_{j=1}^{n} K_{i j} \cdot q_{i j} \cdot k_{i j}=T_{i} \cdot Q_{i}, \\
\ldots, \\
\sum_{j=1}^{n} K_{m j} \cdot q_{m j} \cdot k_{m j}=T_{m} \cdot Q_{m},
\end{array}\right.
$$

where $K_{1 j}, K_{i j}, K_{m j}$ - work quantities of the $j$-th technological process for the first, the $i$-th and the $m$-th project $(j=1, n),(i=1, m)$;

$n$ - technological processes;

$m$ - total amount of projects;

$q_{1 j}, q_{i j}, q_{m j}$ - time norm of the $j$-th technological process for the first, the $i$-th and the $m$-th project;

$k_{1 j}, k_{i j}, k_{m j}$ - coefficient, evaluating subjective time losses because of various subjective causes (shortage of materials, bad weather, etc.) for the first, the $i$-th and the $m$-th project;

$T_{1}, T_{i}, T_{m}$ - total duration of works for the first, the $i$-th and the $m$-th project;

$Q_{1}, Q_{i}, Q_{m}$ - total number of workers for the first, the $i$-th and the $m$-th project.

Time norm cannot be equal to zero, therefore:

$$
q_{i j}>0,(j=1, n) .
$$

From the theoretical point of view, the time norm should not change, however practice shows that in every project it will be different. Sometimes it happens because of objective reasons - when workers acquire skills, when new materials or new technologies are used. However sometimes casual variations also appear. When traditional methods are used [6], such cases are eliminated. In our case there are no possibilities to eliminate casual values. Therefore the reliability of the estimated time norm is determined. In order that accidental measurement values would not be in a system of equations, allowable limits of norm change are defined:

$$
q_{i j} \geq q_{b j}-k \cdot s_{j}, \quad q_{i j} \leq q_{b j}+k \cdot s_{j},
$$

where $q_{b j}$ is the base of the $j$-th technological process time norm;

$s_{j}$ - standard deviation;

$k$ - coefficient defining the probability limits of the determined time norm. One should seek the value of $k$ to be smaller.

At the beginning the base of time norm can be found from technical documentation or practice, when several measurements are made this base of time norm can be calculated according to normal distribution like a virtual time norm:

$$
q_{b j}=\frac{q_{\min }+4 q_{\text {mid }}+q_{\max }}{6},
$$

$q_{\text {mid }}$ - the most likely value of time norm;

$q_{\text {min }}$ - the minimum value of time norm;

$q_{\max }$ - the maximum value of time norm.

Standard deviations $s_{j}$ are calculated by formulas:

$$
s_{j}=\sqrt{\frac{\sum_{i=1}^{m}\left(q_{i j}-q_{j}\right)^{2}}{m}},
$$

where $q_{j}$ is the average time value for unit of the $j$-th technological process.

Limits of the time norm change depend on the accuracy required. One should seek the value of the coefficient defining the probability limits of the determined time norm $k$ to be smaller. If it is assumed that calculations should be performed with $99,7 \%$ accuracy, $k=3$.

In order the calculated values of the time norm satisfy the system of equations (9) at the maximum, the sum of square residuals (SSR) is minimised [10]:

$$
\operatorname{Min}(S S R)=\sum_{i=1}^{m} \sum_{j=1}^{n}\left(q_{i j}-q_{b j}\right)^{2} .
$$

In this way the problem becomes the programming task, the result of which is the estimated time norm satisfying the system of equations (9). 


\section{Example of calculations}

Let's say duration measurements of two technological processes in three constructional projects are performed. Work duration for 5 workers in the first project was 10.4 hours, in the second 7, and in the third one 38 hours. Quantity of the first technological process in the first project was 20 , in the second one 10 , in the third 60. Quantities of the second technological process were such: in the first project 15 , in the second 22, in the third 100. Let's say that coefficient of subjective time losses is equal to 1 in all projects.

We can write system of equations:

$$
\left\{\begin{array}{c}
20 \cdot q_{11} \cdot 1+15 \cdot q_{12} \cdot 1=10.4 \cdot 5, \\
10 \cdot q_{21} \cdot 1+22 \cdot q_{22} \cdot 1=7 \cdot 5, \\
60 \cdot q_{31} \cdot 1+100 \cdot q_{32} \cdot 1=38 \cdot 5 .
\end{array}\right.
$$

Objective function (6):

$$
\begin{gathered}
\operatorname{Min}(S S R)=\left(q_{b 1}-q_{11}\right)^{2}+\left(q_{b 1}-q_{21}\right)^{2}+\left(q_{b 1}-q_{31}\right)^{2}+ \\
+\left(q_{b 2}-q_{12}\right)^{2}+\left(q_{b 2}-q_{22}\right)^{2}+\left(q_{b 2}-q_{32}\right)^{2} .
\end{gathered}
$$

Taking into account the restrictions applied to the time norms (10), (11), solving the programming problem, the following time norms are obtained: $q_{11}=2,133$, $q_{12}=0,623, q_{21}=2,131, q_{22}=0,622, q_{31}=2,131, q_{32}=$ 0,622 . Calculated standard deviations, $s_{1}=0,00084$, $s_{2}=0,00062$ and coefficient $k=1,4$, reliability intervals for the time norm of the first and the second technological process, with the probability of 0,838 , may be determined:

$$
\begin{aligned}
& {\left[q_{b 1}-1,4 s_{1} ; q_{b 1}+1,4 s_{1}\right],[2,130 ; 2,132],} \\
& {\left[q_{b 2}-1,4 s_{2} ; q_{b 2}+1,4 s_{2}\right],[0,621 ; 0,623] .}
\end{aligned}
$$

Virtual time norm of the first technological process $q_{b 1}=2,131$, virtual time norm of the second technological process $q_{b 2}=0,622$.

The results received of time norm dependence on the quantity of works may be presented in the diagram (Fig).

The calculations performed show that often there is a non-linear dependence between time norm and quantity of works (Fig). This phenomenon is called the repetition effect [11].
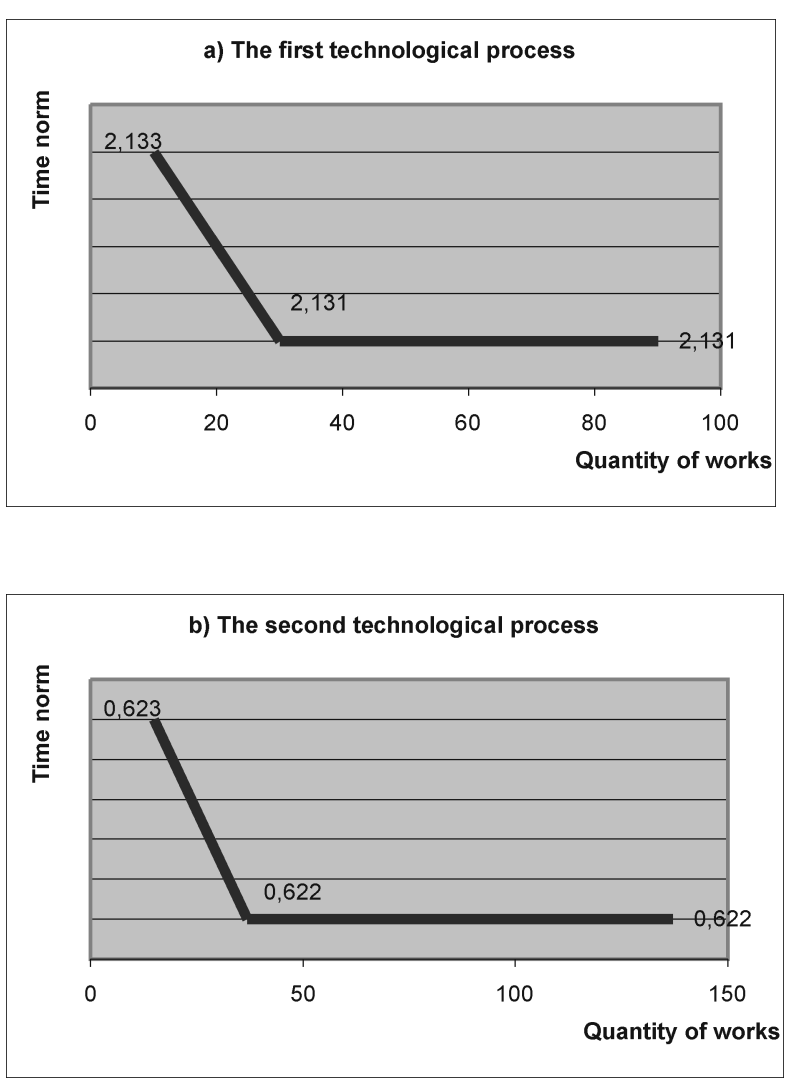

Technological process time norm dependence on the quantity of works

\section{Conclusions}

The methodology presented in the article allows determining the virtual time norm of the technological process by non-traditional methods with a defined probability and without additional expenditures for time rating.

The methodology lets to evaluate the objective changes of the time norm, occurred because of the new materials, new technologies, acquirement of skills and allows making the corrections of the work duration planned. 


\section{References}

1. Chan, D. W. M. and M. M. Kumaraswamy (1996). An evaluation of construction time performance in the building industry. Building and Environment, Vol. 31, No. 6, p. 569-578.

2. Chatzoglou, P. and L. Macaulay (1996). A review of existing models for project management and estimation and the need for a new approach. International Journal of Project Management, Vol. 14, No. 3, p. 173-183.

3. Dawson, R. J. and C. W. Dawson (1998). Practical proposals for managing uncertainty and risk in project planning; International Journal of Project Management, Vol. 16, No. 5, p. 299-310.

4. Leu, S. S., Chen, A. T. and C. H. Yang (2001). A GAbased fuzzy optimal model for construction time-cost trade-off. International Journal of Project Management, Vol. 19, p. 47-58.

5. Proverbs, D.G., Holt, G. D. and P. O. Olomolaiye (1999). Factors impacting construction project duration: a comparison between France, Germany and the U. K. Building and Environment, Vol. 33, p. 197-204.
6. Bagdonas, V. (1981). Technical rating and estimates in civil engineering. Vilnius: Mintis.

7. Harris, F. and R. Mc Caffer (2000). Modern construction management. UK: Blackwell Science (pp. 582).

8. Tamošaitis, R. and L. Gargasaite (2002). Virtual time norms in civil engineering. In: 5 th conference of junior scientists "Lietuva be mokslo - Lietuva be ateities". Vilnius, p. 63-72.

9. Tamošaitis R. and L. Gargasaitè. Modelling of virtual time norms for technological processes. In: Modelling and simulation of business systems (H. Pranevicius, E. Zavadskas, B. Rapp (Ed.)). Kaunas: Technologija, p. 311-316.

10. Koop, G. (2000). Analysis of Economic Data. West Sussex: John Wiley \& Sons.

11. Lam, K. C., Lee, D. and T. Hu (2001). Understanding the effect of the learning-forgetting phenomenon to durations of projects construction. International Journal of Project Management, Vol. 9, No. 7, p. 411-420. 